\title{
BI warehousing system based on big data
}

\author{
Lin Xiangming ${ }^{1, a^{*}}$, Liu Kai ${ }^{2, b^{*}}$, Li Yixuan ${ }^{3, c}$ \\ ${ }^{1}$ School of Economics and Management; Jangxi aviation Vocational \& Technical College \\ ${ }^{2}$ School of Mathematics and Computer, Xinyu University \\ ${ }^{3}$ School of architecture and art, jiangxi industry Vocational \& Technical College
}

\begin{abstract}
In the wave of informatization, the data generated by enterprise operations has increased rapidly, prompting the intelligent development of enterprise warehousing systems. In the development of BI warehousing systems, the application of big data technology can promote the rapid development of business intelligence warehousing systems. The application of big data technology in the BI warehousing system can improve the service quality of the data intelligence of the warehousing system. Based on data, it provides support for corresponding decision-making, thereby improving the enterprise data management system. Therefore, this article mainly conducts research and analysis on the construction of BI warehousing system under the application of big data technology, and aims to provide a certain reference value for similar events in the future through a detailed explanation of the current situation of BI warehousing system construction and big data technology application.
\end{abstract}

\section{INTRODUCTION}

With the rapid increase in data volume, big data technology has been widely used in various industries. The BI warehousing system uses highly integrated and intelligent technology to realize that the warehousing system has simple thinking, learning and perception, and can solve some basic problems in the warehousing field. In the current BI warehousing system construction, the application of big data technology mainly involves smart storage, smart transportation, smart analysis and other activities. The development of BI warehousing can especially provide greater economic benefits to the logistics industry and improve service quality. The role of the same in the establishment of the enterprise's BI warehousing system can completely intelligent development of enterprise warehousing management. Similarly, the application of big data technology in the construction of BI warehousing system can realize the sustainable development of the warehousing system, reduce the consumption of natural and social resources in enterprise warehousing, and promote the improvement of the comprehensive management and control system of the warehousing system. As the main technology of intelligent development, big data technology can promote the healthy development of BI warehousing system with reasonable application.

\section{RELATED WORK}

Research Landscape of Business Intelligence and Big Data analytics[1]. Research on the Design of Smart Warehouse Operation Support Platform Based on Big Data Analysis[2]. Twenty years of research on the adoption, application and success of business intelligence systems [3]. Business intelligence and analytics use, innovation ambidexterity, and firm performance: A dynamic capabilities perspective[4]. Construction of BI warehousing system platform based on big data technology[5]. Value analysis of BI warehousing system development based on real-time data-driven[6]. Business Intelligence Capabilities and Firm Performance: A Study in China[7]. Facilitating speed of internationalization: The roles of business intelligence and organizational agility [8]. Business intelligence governance framework in a university: Universidad de la costa case study[9]. Adaptive Business Intelligence: A New Architectural Approach[10]. Business intelligence and analytics as a driver of dynamic and operational capabilities in times of intense macroeconomic turbulence[11]. In recent years, big data and BI have been widely used in logistics and warehousing, and hardware architecture and software architecture have become popular areas of research. The introduction of big data and BI has injected new impetus into the warehousing system, which can dig deeper into the value of data and open up new profit growth points for enterprises.

\section{Application value of big data technology in BI warehousing system}

\subsection{BI warehousing system}

The BI warehousing system mainly uses business intelligence to analyze and mine the existing data in the warehousing system, so as to realize the expansion of the data, thereby enhancing the commercial value of the data.

"Corresponding author. Email: alxm594@vip.qq.com; bliukai_work@163.com;

c476814305@qq.com 
The establishment of a business intelligence warehousing system can help companies use warehousing data to provide important follow-up support for decision-making. The construction of a business intelligence warehousing system mainly involves warehousing databases, warehousing awareness terminals, and warehousing service platforms. In the current enterprise development, the application of big data technology can promote the rapid development of BI warehousing systems. Big data technology is the key research and development technology for national development. The application of big data technology not only needs to pay attention to hardware technology, but also needs to pay attention to the training of big data talents. The application of big data technology in the BI warehousing system can serve as its basic data support and provide technical support for corresponding decision-making. For example, data analysis and intelligent distribution in BI warehousing systems all rely on the application of big data technology. Data analysis under the same big data technology can also promote the intelligent development of BI warehousing systems, use warehousing data to generate economic value for enterprises, and improve the service level and satisfaction of BI warehousing systems. BI Warehousing hardware system under big data technology is shown in Figure 1.

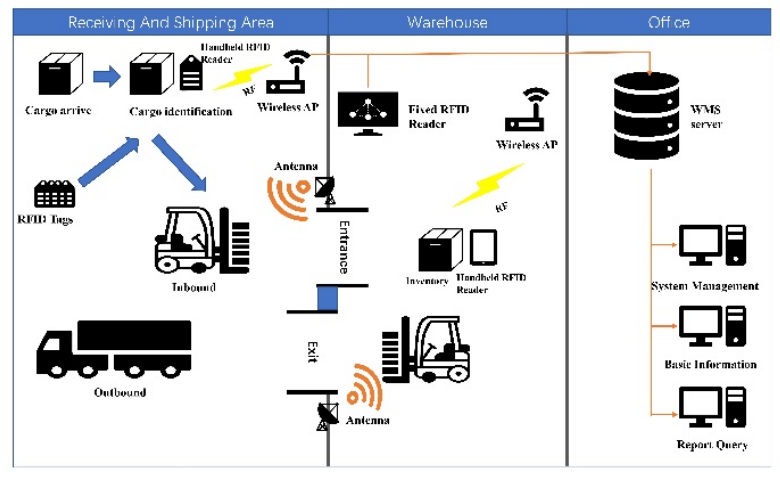

Figure 1 BI Warehousing hardware system under big data technology

In the applied system, Big data logistics warehousing software platform architecture is divided into 4 layers, which are the data generated by various terminals of Data Collection Layer users. The data used is mainly relational database; Data Storage And Analysis Layer is used to store massive amounts Data, using distributed architecture and real-time computing, Data Sharing Layer, in order to improve data processing speed and response time, NOSQL databases (Redis, Hbase) are used, and Data Application Layer is used for OLAP, BI and Business products and logistics reports. as shown in picture 2 .

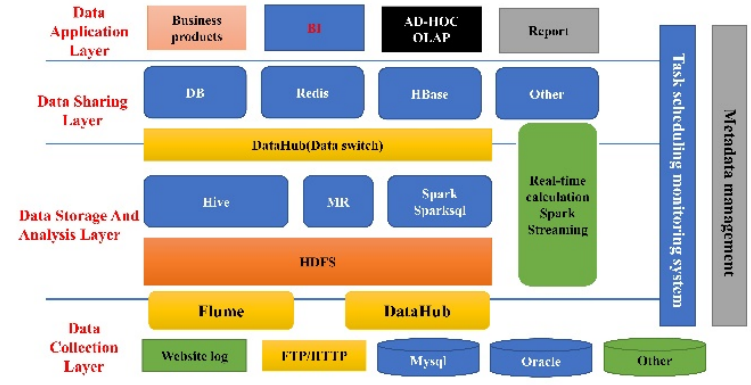

Figure 2 Big data logistics BI warehousing software platform architecture.

\subsection{Application value}

The application of big data technology in the construction of BI warehousing system has improved the data value of enterprise warehousing. Because the previous warehousing system did not perform data processing and analysis on its own huge data stream, the economic benefits generated by it were minimal. In the current big data technology applied to the data of the BI warehousing system, the data can be sorted and analyzed, and the value in the data can be extracted. Through filtering and processing, it can provide convenient and fast data for the managers and users of the BI warehousing system information. The application of big data technology in the construction of BI warehousing system can enhance the market competitiveness of enterprises. Through the mastering and analysis of the detailed data of the BI warehousing system, the information of the storage value can be extracted to provide support for the relevant decision-making of the enterprise. At the same time, the application of big data not only meets the individual needs of users, but also actively responds to fierce market competition, which has a significant impact on the decision-making, management and brand development of enterprises.

In the development of BI warehousing system, it is based on data application. Big data technology is applied to the construction of BI warehousing system, mainly in the four aspects of perception end, transmission channel, storage end, and service platform.

\section{Application of Big Data Technology in the Construction of BI Warehousing System}

In the development of BI warehousing system, it is based on data application. Big data technology is applied to the construction of BI warehousing system, mainly in the four aspects of perception end, transmission channel, storage end, and service platform.

\subsection{Big data technology applied to the perception end of $\mathrm{BI}$ warehousing system}

In the construction of the perception end of the BI warehousing system, realizing the comprehensive 
perception of warehousing information is the basis of the BI warehousing system. The perception end of BI warehousing system is constructed and applied with big data technology, which can accurately collect business operation data, ensure that customers can understand their needs and locations, and also use transportation vehicles to meet customer satisfaction, while also saving economic costs.

\subsection{Big data technology is applied to the transmission channel of $\mathrm{BI}$ warehousing system}

In the construction of the transmission channel of the BI warehousing system, the transmission channel is mainly connected to the data information collection and storage of the warehousing. Similarly, the intelligent warehousing transmission channel can be based on the Internet and communication technology to realize the collection and storage of warehousing information data, which is a big data technology The application provides a good application environment, and also realizes the timely transmission of information and data of the big data BI warehousing system.

\subsection{Big data technology is applied to the storage end of BI warehousing system}

In the current construction of the intelligent end of the BI storage system, the application diversity of the storage end needs to be realized. Big data technology is mainly applied to the storage end of the BI warehousing system with cloud computing as the core. Also, because the massive data information of the BI warehousing system is transmitted to the storage end, it is difficult for traditional data calculation and storage to realize the data receiving and processing.

\subsection{Big data technology applied to the BI warehousing system service platform}

In the construction of the BI warehousing system service platform, the use of big data technology can realize the technical processing and analysis of massive data, and the use of intelligent technologies such as data mining and analysis under the big data technology can realize the intelligent management and control of the BI warehousing system. Similarly, the application of big data technology to the BI warehousing system service platform is a manifestation of its value. The benign operation of the BI warehousing system based on big data technology is an important support for the realization of the BI warehousing system. Through the development, integration and intelligence of big data technology, the intelligent construction of warehousing information services is realized, which not only reduces the low-cost and efficient operation of warehousing, but also improves user satisfaction and provides guarantee for the healthy development of warehousing systems.

\section{CONCLUSION}

The application of big data technology to the construction of the BI warehousing system can realize the intelligent development of the system and realize the transformation of the enterprise to the intelligent management industry. Similarly, big data technology is used as the basis of the business intelligence warehousing system. By combining technology and smart warehousing management, the level of warehousing intelligence is improved, thereby continuously promoting the development of smart warehousing. In the development of BI warehousing system, the continuous introduction and application of big data technology can promote the smarter warehousing system, so that enterprises can improve more convenient services, reduce the cost of warehousing management, and reduce the consumption of natural resources and human resources. The healthy development of the enterprise is escorted.

\section{AUTHORS' CONTRIBUTIONS}

Liu Kai is responsible for the design of BI warehousing system based on big data hardware and software, and writing papers, and Lin Xiangmin is responsible for enterprise implementation and research.

\section{ACKNOWLEDGMENTS}

Thank the work unit for giving us a superior platform to write papers and obtain experimental data, thank the partners for their strong support, and thank the family for their selfless dedication. Without your support, we would not be successful.

\section{REFERENCES}

1. Liang, T.-P. and Y.-H. Liu, Research Landscape of Business Intelligence and Big Data analytics: A bibliometrics study. Expert Systems with Applications, 2018. 111: p. 2-10 DOI:https://doi.org/10.1016/j.eswa.2018.05.018.

2. Xing Puxue, L.Q., Research on the Design of Smart Warehouse Operation Support Platform Based on Big Data Analysis. Technology Innovation and Application, 2018. 2018: p. 86-87.

3. Ain, N., et al., Two decades of research on business intelligence system adoption, utilization and success - A systematic literature review. Decision Support Systems, 2019. 125 DOI:https://doi.org/10.1016/j.dss.2019.113113.

4. Božič, K. and V. Dimovski, Business intelligence and analytics use, innovation ambidexterity, and firm performance: A dynamic capabilities perspective. The Journal of Strategic Information Systems, 2019. 28(4) DOI:https://doi.org/10.1016/j.jsis.2019.101578.

5. Ruiji, L., Construction of BI warehousing system platform based on big data technology. GuangDong Canye, 2019. 53: p. 55-57 
DOI:https://doi.org/10.3969/j.issn.2095-

1205.2019.12.33.

6. Ruiji, L., Value analysis of BI warehousing system development based on real-time data-driven. Industry and Technology, 2019. 19: p. 51-52.

7. Chen, Y. and Z. Lin, Business Intelligence Capabilities and Firm Performance: A Study in China. International Journal of Information Management, 2020

DOI:https://doi.org/10.1016/j.ijinfomgt.2020.10223 2.

8. Cheng, C., H. Zhong, and L. Cao, Facilitating speed of internationalization: The roles of business intelligence and organizational agility. Journal of Business Research, 2020. 110: p. 95-103 DOI:https://doi.org/10.1016/j.jbusres.2020.01.003.

9. Combita Niño, H.A., J.P. Cómbita Niño, and R. Morales Ortega, Business intelligence governance framework in a university: Universidad de la costa case study. International Journal of Information Management, 2020. 50: p. 405-412 DOI:https://doi.org/10.1016/j.ijinfomgt.2018.11.012.

10. João Lopes*, T.G., Manuel Filipe Santos, Adaptive Business Intelligence: A New Architectural Approach. Procedia Computer Science, 2020. 177: p. 540-545

DOI:https://doi.org/10.1016/j.procs.2020.10.075.

11. Moreno, V., F. Cavazotte, and W. de Souza Carvalho, Business intelligence and analytics as a driver of dynamic and operational capabilities in times of intense macroeconomic turbulence. The Journal of High Technology Management Research, 2020. 31(2) DOI:https://doi.org/10.1016/j.hitech.2020.100389. 